\title{
Temperature and Damage Impact on the Permeability of Opalinus Clay
}

\author{
Mohammad Monfared • Jean Sulem • \\ Pierre Delage $\cdot$ Mehrdokht Mohajerani
}

Received: 18 June 2012/ Accepted: 22 July 2013/Published online: 11 August 2013

(C) Springer-Verlag Wien 2013

\begin{abstract}
The effects of temperature on the water transport properties of intact and damaged Opalinus (OPA) clay are investigated by using a recently developed hollow cylinder triaxial cell [Monfared (Int J Rock Mech Min Sci 48:637-649, 2011b)] that allows full saturation and drainage conditions in low-permeability clays and shales. The volumetric response of saturated OPA clay sample during a drained heating test shows an irreversible contraction after a temperature threshold. The permeability tests which are performed before and after the heating test show that the induced irreversible sample contraction by thermal loading reduces the permeability of OPA clay sample. In order to study the effect of temperature on the permeability of a damaged sample of OPA clay, the permeability tests are performed on a saturated sample previously sheared by a standard drained triaxial loading. The test results show no significant effect of shear-type damage on the permeability of the sample at $25{ }^{\circ} \mathrm{C}$ and $80{ }^{\circ} \mathrm{C}$. The experimental results presented in this paper show the crucial role of the thermally induced strains on sample permeability. Thermo-elastic dilation leads to a slight increase of the permeability, whereas thermoplastic contraction leads to a reduction.
\end{abstract}

Keywords THM behaviour - Shale - Permeability · Damage $\cdot$ Thermal contraction

M. Monfared · J. Sulem $\cdot$ P. Delage $\cdot$ M. Mohajerani École des Ponts Paris Tech, UR Navier-CERMES, CNRS UMR 8205, Université Paris-Est, 6-8 av. Blaise Pascal, 77455 Marne-la-Vallée cedex 2, France

Present Address:

M. Monfared ( $\square)$

BG Consulting Engineers, Lausanne, Switzerland

e-mail: mohammad.monfared@bg-21.com

\section{Introduction}

The storage of high-/intermediate-level exothermic radioactive waste in low-permeability geological formations at great depth is a potential solution to limit their short- and long-term hazardous effects. In this context, clayey soils and rocks as natural barriers are interesting candidates due to their very low permeability, high radionuclides retention capacities and good self-sealing properties. To ensure the long-term performance of the waste disposal system, the effect of heat emitted by the waste on the hydro-mechanical properties of the natural barriers should be studied. In particular, the effect of the heat on the damaged zone around the underground galleries should be investigated. This damage zone, known as the excavation damage zone (EDZ), is mainly induced by the redistribution of stresses during the gallery excavation process. The material in the EDZ presents weaker mechanical properties and higher permeability compared to the intact formation. The heat induced by the waste could alter more of these properties and jeopardise the performance of the underground repository.

The anomalous response of clayey soils during the drained heating tests have been shown by many authors (e.g. Campanella and Mitchell 1968; Hueckel and Borsetto 1990; Delage et al. 2000; Cekerevac and Laloui 2004; Sulem et al. 2004). These results reveal that the normally consolidated samples contract upon heating, but the standard dilation behaviour has been observed for highly overconsolidated samples. A mixed dilation-contraction behaviour has been observed for low overconsolidated samples. The effect of temperature increase on clayey rocks has been less studied in the literature. The works of Jobmann and Polster (2007), Kull et al. (2007), Zhang et al. (2007) and Monfared et al. (2011a) on the Opalinus (OPA) clay (from Switzerland) and Mohajerani et al. (2013) on 
the Callovo-Oxfordian claystone (from France) have shown comparable response (dilation, contraction or mixed behaviour). However, the notions of preconsolidation pressure and overconsolidation ratio (OCR) as defined in soil mechanics are not well defined for clayey rocks (Mohajerani et al. 2011).

The data on the effects of temperature on the hydromechanical behaviour of damaged clayey materials are scarce in the literature. Recently, Monfared et al. (2012) evidenced the phenomenon of 'thermal' failure in a saturated Boom clay sample, where a pre-existing shear band turned into a preferential failure plane during an undrained heating test. The effects of temperature on the permeability of intact clayey soils have been studied by Habibagahi (1977), Morin and Silva (1984) an Delage et al. (2000). Their results show that the observed increase in hydraulic conductivity with temperature is mainly due to the decrease in water viscosity; however, the intrinsic permeability remains almost unchanged. The effect of temperature on a damaged clayey soil has been examined by Monfared et al. (2012). They tested a sample of Boom clay that was sheared following a standard path in the drained condition. They showed that the shear band has no significant effect on the intrinsic permeability of the sample, at both 25 and $80^{\circ} \mathrm{C}$.

In this work, the effect of temperature on the permeability of intact and damaged samples of OPA clay is investigated. To do so, two hollow cylinder samples are carefully saturated in a hollow cylinder triaxial cell that was developed during the TIMODAZ European research project (Monfared et al. 2011b). Due to the low permeability of OPA clay, a transient method is used to estimate the permeability of the samples. The effect of the irreversible thermal contraction on the transport properties of OPA clay is investigated by performing the permeability tests before and after heating cycles between $25^{\circ} \mathrm{C}$ and $80{ }^{\circ} \mathrm{C}$ on the first sample. The effect of temperature on the permeability of damaged OPA clay sample is studied on the second sample. The permeability tests are performed at 25 and $80{ }^{\circ} \mathrm{C}$ on this sample, which is previously damaged by a standard drained triaxial loading.

\section{Material and Set Up}

All tests in this study are performed in a new hollow cylinder triaxial cell with a short drainage path specially designed to study the thermo-hydro-mechanical behaviour of low-permeability materials (Fig. 1a, b). A detailed description of the experimental set up can be found in Monfared et al. (2011b). Hollow cylinder specimens have an internal diameter $\left(\varphi_{\text {int }}\right)$ of $60 \mathrm{~mm}$, an external diameter $\left(\varphi_{\text {ext }}\right)$ of $100 \mathrm{~mm}$ and a height $(H)$ of $75-80 \mathrm{~mm}$. The same confining pressure is applied to both the inner and outer faces of the sample in order to maintain a standard triaxial condition. As shown in Fig. 1, a major advantage of this device is related to the lateral fluid connections at the internal and external walls of the hollow cylinder sample that allow lateral drainage through two geotextile bands with a height between $H / 2$ and $H / 3$ placed in the middle height of the sample. The drainage path, thus reduced to half of the thickness of the sample $(10 \mathrm{~mm})$, significantly reduces the time needed to saturate the sample, as well as that needed to perform fully drained thermo-mechanical tests.

The cell is equipped with a local strain measurement system by linear variable differential transformer (LVDT) transducers, a temperature regulator system (precision $\pm 0.1 \mathrm{C}$ ) and two pressure transducers connected to the external wall and to the base of the sample (the transducers' connections could be changed according to the planned test). The pore pressure and the confining pressure are applied by means of four pressure volume controllers (PVCs), see Fig. 1b. An immersed load cell in direct contact with the sample is used to monitor the axial load during shearing.

Two hollow cylinder samples are trimmed from 100-mm-diameter cores of OPA clay provided by Nagra, the Swiss agency of radioactive waste management. The cores are extracted from the underground research laboratory (URL) of Mont Terri in Switzerland. The first sample (OP1) is trimmed from the core that was extracted at a distance of around $1 \mathrm{~m}$ from the tunnel wall, while this distance is around $9 \mathrm{~m}$ for the second sample (OP2). The inner hole of the samples is cored in dry conditions using a diamond coring bit $60 \mathrm{~mm}$ in diameter.

Both samples belong to the shaly facies of OPA clay formation, which contains approximately $65 \%$ clay minerals [illite $(17 \%)$, illite-smectite mixed layer $(10 \%)$, chlorite (8\%) and kaolinite (30\%)] and $35 \%$ non-clayey minerals, composed of $20 \%$ quartz, $11 \%$ carbonate $(8 \%$ calcite, $1 \%$ dolomite/ankerite, $2 \%$ siderite), $2.5 \%$ framework silicate (albites, K-feldspar) and a small amount of pyrite (1\%) and organic carbon (0.5\%) (Mazurek 1999). The total claystone porosity deduced from oven drying at $105{ }^{\circ} \mathrm{C}$ during a period of $24 \mathrm{~h}$ is around $18 \%$, whereas the mercury intruded porosity measured by Muñoz (2006) at a maximum pressure of $219 \mathrm{MPa}$ is between 9 and $11 \%$.

\section{Sample Saturation}

In order to minimize damages induced by free swelling during the sample saturation, Delage et al. (2007) proposed to saturate the sample under equivalent in situ effective stress. The in situ stress at the level of the Mont Terri URL is highly anisotropic, with $\sigma_{1}=6,000-7,000, \sigma_{2}=$ 4,000-5,000 and $\sigma_{3}=600-2,000 \mathrm{kPa}$ (Martin and Lanyon 2003). Because of the technical difficulty in applying the 
Fig. 1 a Hollow cylinder triaxial cell. b General setting of the hydraulic connections (a)

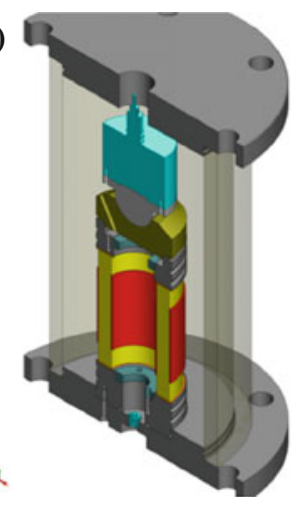

(b)

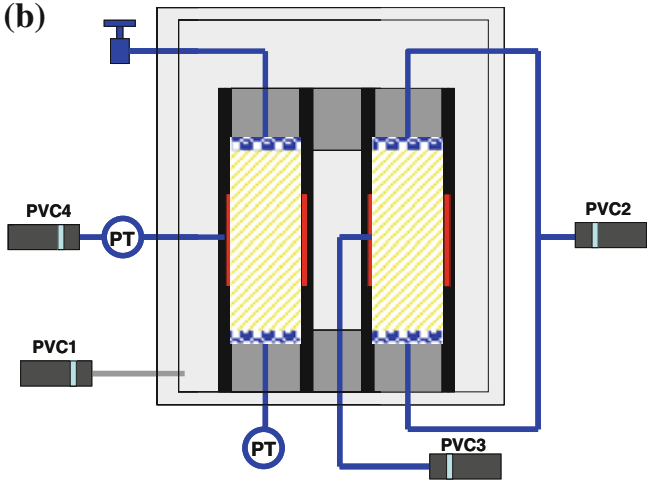

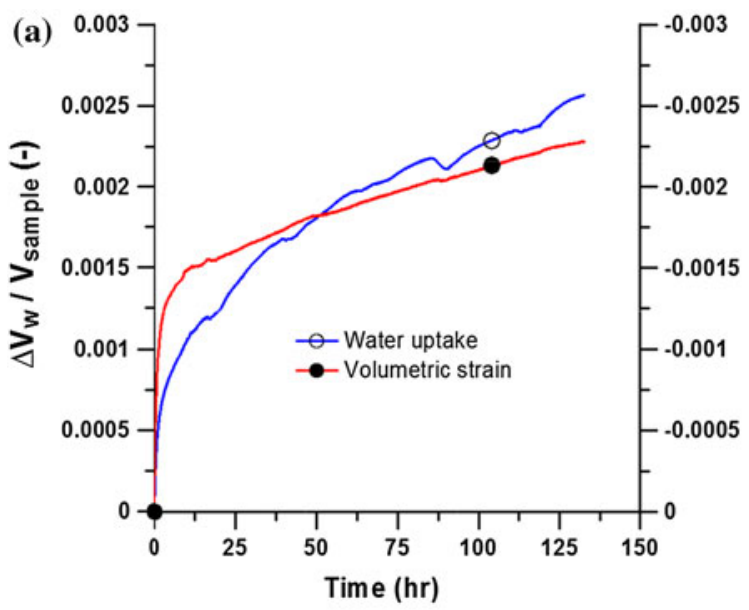

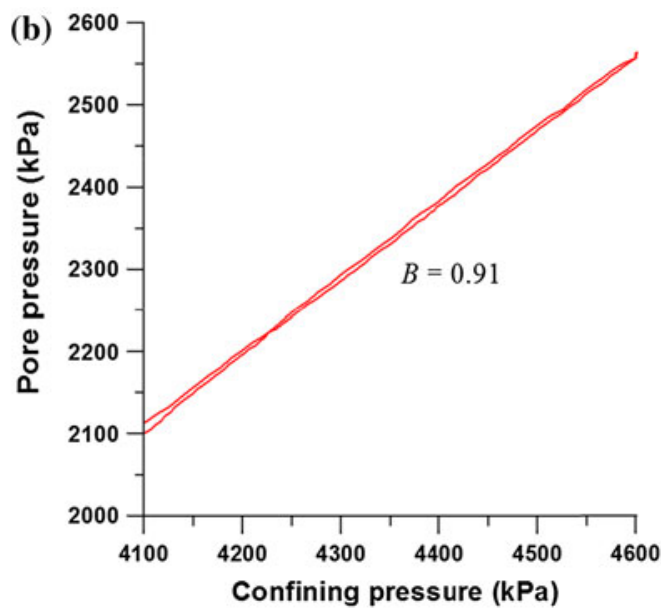

Fig. 2 Sample saturation under equivalent in situ stress condition: a sample volume change and water uptake, b undrained isotropic compression test after sample saturation to evaluate the Skempton coefficient $B$

in situ anisotropic stress, the resaturation process is performed under an equivalent isotropic stress equal to the in situ total mean stress $(4,100 \mathrm{kPa})$ and a back-pressure equal to the in situ pore water pressure $(2,200 \mathrm{kPa})$. The back-pressure is applied through the four drainage connections to accelerate the sample saturation. Figure 2 presents a typical response of OPA clay sample during the saturation phase. The initial water content of the sample is $6.7 \%$. This value is lower than that of a saturated sample $(8.7 \%)$ (Muñoz 2006). The normalised sample water uptake as well as the sample volumetric response are presented in Fig. 2a. This figure shows a bilinear response for both curves. We observe a steep change in the sample water uptake and volume change after $20 \mathrm{~h}$, followed by a gentler slope with a constant rate. Monfared et al. (2011b) have shown that the first part of the curve is related to the reduction of the sample suction from its initial value down to zero. The decrease of suction reduces the effective stress, which induces the observed dilation of the sample. The second part of the curve could be attributed to the hydro-chemo-mechanical interaction between the clayey minerals and water. When water evaporates from the sample, the minerals dissolved in the pore fluid remain in the sample. During the saturation process with demineralised water, first, the biggest pores (macro pores) are filled and the concentration of the ions reduces in these pores. The disequilibrium between the ionic concentration in the macro and micro pores that are present in the structure of clay minerals provokes an osmotic mechanism, which results in water absorption by the micro pores and, consequently, to additional sample dilation. Note that this mechanism is active from the beginning of the saturation phase and stops once the osmotic potential dissipates.

To verify the good sample saturation, the Skempton coefficient $B$ is evaluated at the end of the saturation phase. Figure $2 \mathrm{~b}$ presents the evolution of the water pore pressure as a function of the confining pressure during undrained loading. The slope of this curve gives direct access to the Skempton coefficient $B$, which is 0.91 . This value should be corrected to consider the effect of compressibility of the drainage system, as done by Monfared et al. (2011b). This correction gives a value of 0.94 for the coefficient $B$. Monfared et al. (2011a) showed that the theoretical value of $B$ for saturated OPA clay is 0.96 , which is very 


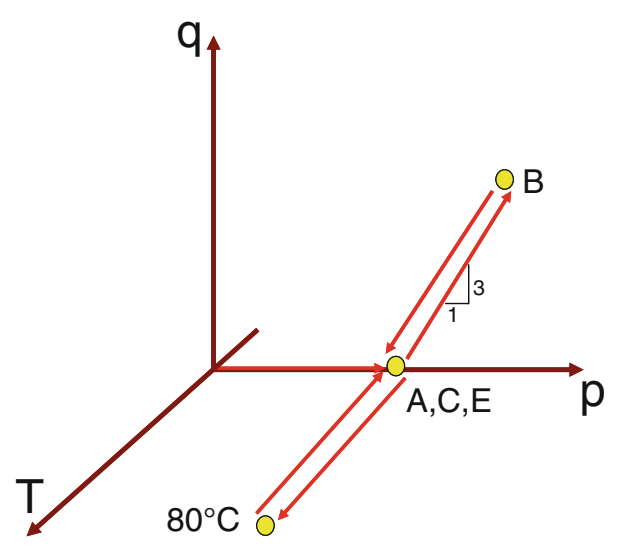

Fig. 3 Stress path followed for sample OP2 to estimate the effect of temperature on the permeability of the damaged material

close to the result obtained by this experiment, which confirms the good sample saturation.

\section{Testing Program and Experimental Results}

Two hollow cylinder samples of OPA clay, OP1 and OP2, both with bedding planes parallel to their axis, have been prepared. Note that it would be very difficult to prepare hollow cylinder samples with bedding planes normal to the axis because of discing. Sample OP1 is submitted to two heating-cooling cycles between 25 and $83{ }^{\circ} \mathrm{C}$. Permeability tests are carried out before and after the thermal cycles to investigate the effect of temperature-induced deformation on the transport properties of intact OPA clay sample. Sample OP2 is tested to investigate the effect of temperature on the permeability of the damaged sample. As shown in Fig. 3, once saturated (point A), the sample is first sheared in the drained condition up to peak stress (B). After releasing the shear stress $(\mathrm{C})$, the sample is submitted to a drained heating-cooling cycle between 25 and $80{ }^{\circ} \mathrm{C}$. The permeability of the sample is measured after sample saturation (A), after shear unloading (C), at $80{ }^{\circ} \mathrm{C}$ (D) and, finally, after cooling at $25^{\circ} \mathrm{C}(\mathrm{E})$.

\subsection{Effect of Drained Heating on Opalinus Clay Permeability-Test OP1}

Once saturated, sample OP1 is subjected to two heatingcooling cycles while all four sample drainages are open. Figure 4 recalls the sample volumetric response during this test (Monfared et al. 2011a). This figure shows an initial quasi-linear thermo-elastic expansion phase between 25 and $60{ }^{\circ} \mathrm{C}$ (with a rate of $5.9 \times 10^{-5}{ }^{\circ} \mathrm{C}^{-1}$ ), followed by a transition phase and a plastic contraction that starts at $68{ }^{\circ} \mathrm{C}$ and becomes significant and linear between 70 and

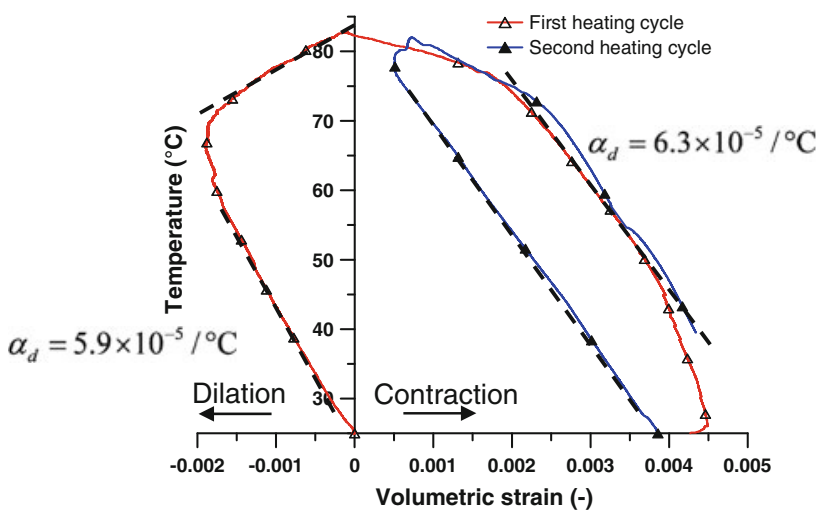

Fig. 4 Drained thermal volume changes under in situ stress conditions, test OP1

$83{ }^{\circ} \mathrm{C}$ (with a rate of $-1 \times 10^{-4}{ }^{\circ} \mathrm{C}^{-1}$ ). During subsequent cooling, the sample quasi-linearly contracts with a rate of $6.3 \times 10^{-5}{ }^{\circ} \mathrm{C}^{-1}$, which is close to that of the first heating expansion phase $\left(5.9 \times 10^{-5}{ }^{\circ} \mathrm{C}^{-1}\right)$. An irreversible contraction of $0.45 \%$ is finally obtained after the first cycle. The second temperature cycle exhibits a quasireversible linear thermo-elastic response (with a similar rate as that during the first cooling phase), with a quasilinear expansion up to $80{ }^{\circ} \mathrm{C}$, followed by a parallel contraction curve when the temperature is decreased.

Once heated up to $83{ }^{\circ} \mathrm{C}$, the sample keeps expanding up to $80{ }^{\circ} \mathrm{C}$ (the new maximum temperature supported) during the second cycle, with no longer memory of the previous temperature threshold of $65{ }^{\circ} \mathrm{C}$. Interestingly, this temperature is close to the maximum temperature previously experienced by OPA clay. Indeed, the geological history provides a maximum burial depth of the OPA clay at Mont Terri of about 1,000 m (Marschall et al. 2005). Thus, the value of $65^{\circ} \mathrm{C}$ appears as a plausible maximum temperature previously experienced by the material. This response seems to indicate that the claystone retained the memory of its maximum supported temperature, much like overconsolidated soils conserve the memory of the maximum supported load. The observed behaviour is, hence, typical of thermal hardening, with an elastic thermal expansion observed below the maximum supported temperature, followed by a plastic contraction at thermal yielding once the maximum temperature is attained.

The effect of the irreversible thermal contraction on the hydraulic properties of sample OP1 is investigated by performing two permeability tests before and after the thermal cycles.

Permeability measurements in the steady-state condition are known to be difficult in low-permeability materials because of: (i) the long time needed to achieve the steadystate condition, (ii) the difficulty of measuring very small water volumes exchange, (iii) the discrepancy that is often 

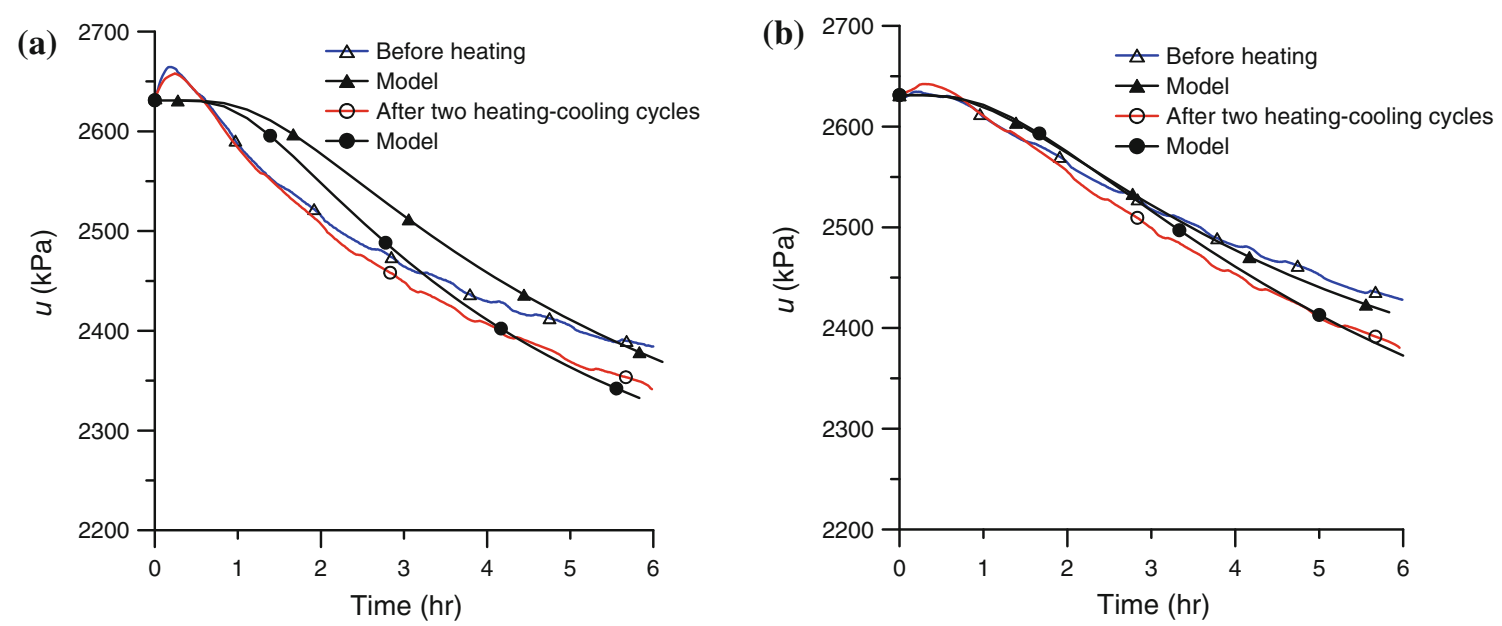

Fig. 5 Permeability tests on sample OP1, before and after two heating-cooling cycles; pore pressure dissipation phase: a pressure response from the internal wall of the sample, $\mathbf{b}$ pressure response from the top of the sample

observed between the input and output fluxes, e.g. Coll (2005). To overcome these problems, a transient method is adopted. Among the various transient methods in the literature, e.g. Brace et al. (1968), Hart and Wang (2001), Ai et al. (2001), Scherer (2006) and Ghabezloo et al. (2009), the one proposed by Ghabezloo et al. (2009) is used. The method first consists of inducing an excess pore pressure in the sample by performing an isotropic undrained compression test. The second stage consists of releasing the excess pore pressure on one side of the sample while monitoring the pore pressure change on the other side. The permeability is evaluated through the back-analysis of the experimental results by solving pore pressure diffusion equations.

Starting from the in situ mean effective stress $\left(\sigma_{3}=4,100 \mathrm{kPa}\right.$ and $\left.u=2,200 \mathrm{kPa}\right)$, both permeability tests are carried out by increasing the confining pressure from 4,100 to $4,600 \mathrm{kPa}$ in the undrained condition, i.e. after closing all the drainage valves connected to the PVCs. The excess pore pressure is then allowed to dissipate by connecting the lateral external drainage and the base drainage to the PVCs, imposing a constant pressure of $2,200 \mathrm{kPa}$. The pore pressure dissipation is monitored by two pressure transducers located at the top and on the internal wall of the sample. The water expelled from the sample is measured by the PVCs connected to the lateral external drainage and to the bottom drainage. Figure 5 shows the response of the pressure transducers during the pore water pressure dissipation phase for the two permeability tests performed before and after the thermal cycle. Figure 6 presents the water volume expelled from the sample during this phase. The responses of the two pressure transducers and the water exchanges are back-analysed to estimate the permeability. We recall that the sample axis is parallel to the bedding planes. The permeability in the direction parallel to bedding is expected to be higher than

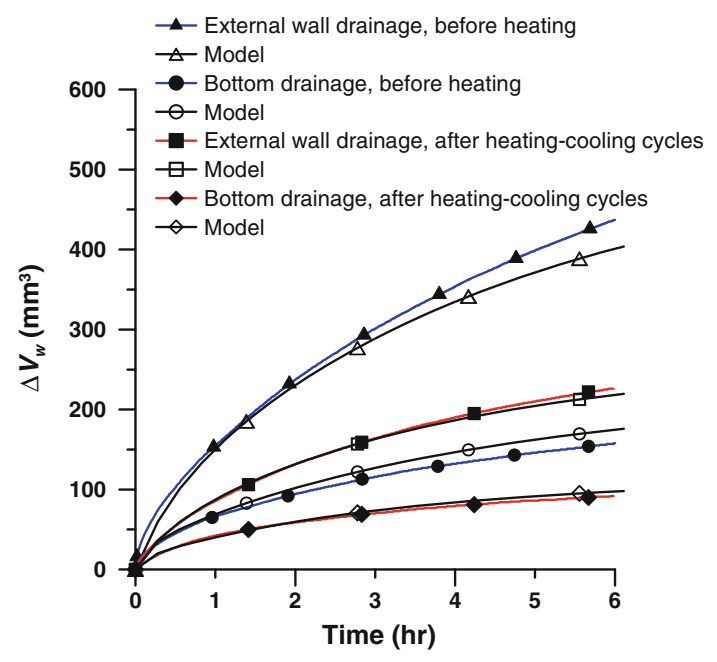

Fig. 6 Permeability tests on sample OP1 before and after two heating-cooling cycles; water volume expelled from the sample during the pore pressure dissipation phase

that along the direction normal to it. Regarding the cylindrical shape of the sample, this situation results in a pore pressure diffusion pattern which is not axisymmetric. Thus, a $3 \mathrm{D}$ analysis is needed to correctly estimate the permeability in the directions parallel and perpendicular to the bedding. The Z_Soil.PC (@Zace Service Ltd.) finite element code is used to simulate the permeability tests. This software permits to perform a fully coupled hydromechanical analysis. It can account for anisotropic hydraulic diffusivity, but not for anisotropic mechanical properties. Pore pressure diffusion is expressed by:

$\frac{d u}{d t}=\frac{1}{\mu_{\mathrm{w}} S}\left(k_{\mathrm{x}} \frac{\partial^{2} u}{\partial x^{2}}+k_{\mathrm{y}} \frac{\partial^{2} u}{\partial y^{2}}+k_{z} \frac{\partial^{2} u}{\partial z^{2}}\right)$

where $u$ is the pore pressure, $t$ is time, $\mu_{\mathrm{w}}$ is the dynamic water viscosity, $S$ is the storage coefficient and $k_{\mathrm{x}}=k_{\mathrm{z}}$ are 
Fig. 7 Pore pressure distribution at the end of the permeability test (after $6 \mathrm{~h}$ ) on OP1: a anisotropic permeability assumption, b isotropic permeability assumption

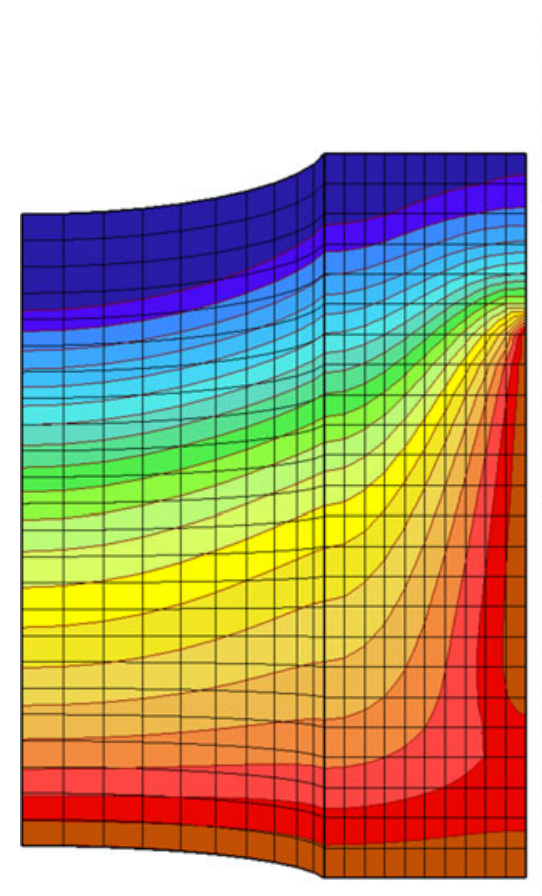

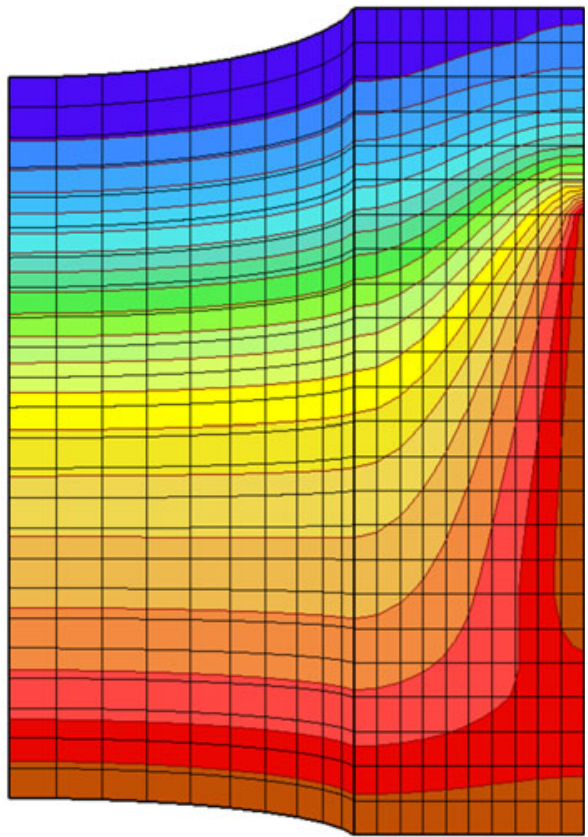
UNIT
[WN/m2] the permeability along the bedding plane and $k_{\mathrm{y}}$ is the permeability perpendicular to the bedding. A constant and homogenous pressure equal to the pressure at the end of undrained isotropic phase $(2,640 \mathrm{kPa})$ is set as the initial pore pressure. At the base and external wall of the sample, a constant water pressure equal to $2,200 \mathrm{kPa}$ is prescribed and the other boundaries of the sample are considered as impervious. Figure 7 a presents the pore pressure diffusion pattern in one quarter of the sample at the end of the first permeability test, $6 \mathrm{~h}$, by considering the permeability parallel and perpendicular to the bedding equal to $4.5 \times 10^{-20}$ and $3.2 \times 10^{-20} \mathrm{~m}^{2}$, respectively. In this computation, the storage coefficient of the sample is taken to be equal to $4.3 \times 10^{-6} \mathrm{kPa}^{-1}$. For the sake of comparison, the pore pressure diffusion in a sample with isotropic permeability equal to $4.5 \times 10^{-20} \mathrm{~m}^{2}$, with the same storage coefficient and similar initial and boundary conditions, is presented in Fig. 7b. In these figures, the pore pressure value is shown as negative regarding the sign convention adopted in the Z_Soil.PC finite element program (positive in tension and negative in compression). Figure $7 \mathrm{a}, \mathrm{b}$ show two different pore pressure distribution patterns and the deviation of the pore pressure pattern from the horizontal line at the centre of the sample in Fig. 7a illustrates clearly the effect of anisotropic permeability. To simulate the response of the pressure transducer connected to the top and internal wall of the sample, an average pore pressure over all nodes at the top and internal drainage surfaces is calculated, respectively. The water exchanges between the sample and the PVCs connected to the external and bottom drainages are simulated by summing the flux over all elements placed at the external and bottom drainages surfaces, respectively.

Figures 5 and 6 show the comparison between the experimental results and the best-fit numerical results for pore pressure and water exchange, respectively. In Fig. 5, we observe an initial increase of the measured pore pressure. This can be attributed to the so-called Mandel-Cryer effect, which is a typical consequence of the poromechanical coupling (Verruijt 2013). When the pore pressure at one boundary starts to dissipate, the resulting local deformation may lead to an immediate effect in other parts of the sample, and this may lead to an additional pore pressure. This effect is more pronounced in the response of pore pressure measured on the internal wall (Fig. 5a) than that measured at the top of the sample (Fig. 5b), which reflects the effect of sample mechanical anisotropy. The present model, which assumes mechanical isotropy as explained previously, is not able to capture this fine aspect of the experimental results. Therefore, the estimated permeability should be seen as an approximate value. However, this approximation is acceptable. The estimated permeability of the sample parallel and perpendicular to the bedding before the heating cycles are $4.5 \times 10^{-20}$ and $3.2 \times 10^{-20} \mathrm{~m}^{2}$, respectively. The storage coefficient of the sample is evaluated to be equal to $4.3 \times 10^{-6} \mathrm{kPa}^{-1}$. After the heating cycles, the estimated permeability parallel to the bedding reduces to $2.8 \times 10^{-20} \mathrm{~m}^{2}$ and that 
perpendicular to the bedding reduces to $2.0 \times 10^{-20} \mathrm{~m}^{2}$. The estimated storage coefficient of the sample also reduces to $1.9 \times 10^{-6} \mathrm{kPa}^{-1}$. The irreversible volumetric strain as shown in Fig. 4 results in a sample porosity reduction, which could explain the decrease of the sample permeability after the heating cycles. The simultaneous reduction of the permeability and of the storage coefficient (with a dominant effect of the decrease of the storage coefficient) could explain the faster pore pressure dissipation (Fig. 5) associated with a reduction of the quantity of water expelled from the sample (Fig. 6) during the permeability test after heating cycles compared to that before the first heating test.

\subsection{Effect of Temperature on the Permeability} of the Damaged Sample-Test OP2

Once saturated, sample OP2 is sheared in drained conditions. During this test, the confining pressure and pore water pressure are maintained constant at 4,100 and $2,200 \mathrm{kPa}$, respectively, and all four drainages are kept open in order to a ensure satisfactorily drained condition. The $q-\varepsilon_{\mathrm{axial}}$ and $\varepsilon_{\mathrm{vol}}-\varepsilon_{\mathrm{axial}}$ curves are presented in Fig. 8 .

The maximum shear stress $(7,191 \mathrm{kPa})$ is reached at $1.8 \%$ axial strain. The sample volumetric strain response is divided into a contracting phase up to $1 \%$ of the axial strain, followed by a dilation phase related to strain localisation.

\subsubsection{Permeability Measurement}

Permeability measurements are performed on sample OP2 after sample saturation (A), after shearing (C), after heating

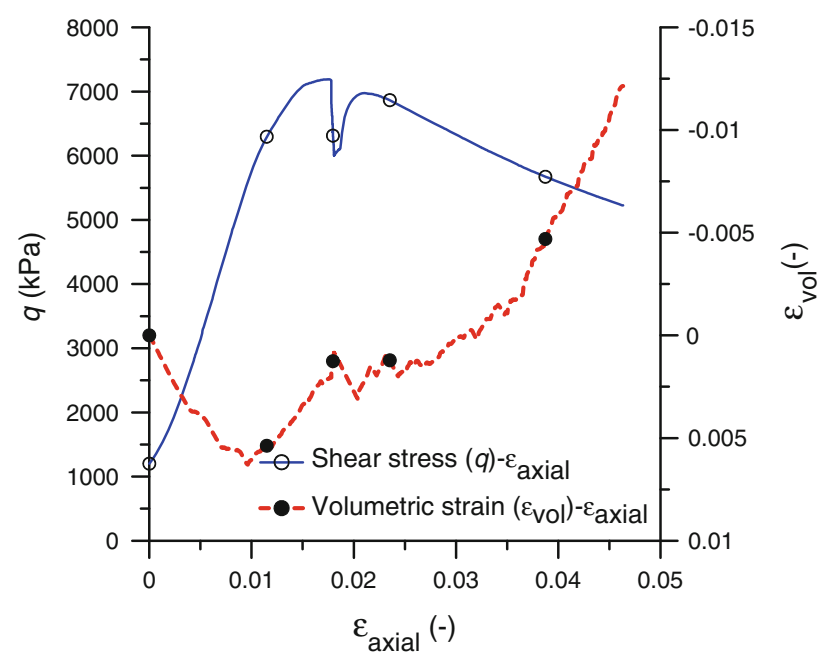

Fig. 8 Drained shear test on sample OP2; shear stress and volumetric strain versus axial strain the sheared sample in the drained condition up to $80{ }^{\circ} \mathrm{C}$ (D) and, finally, after cooling down to $25^{\circ} \mathrm{C}$ (E) (see Fig. 3). In state $\mathrm{C}$, the sample has been loaded up to the maximum deviator and unloaded. As observed, once the sample has been taken out of the cell, this shear loading has induced the formation of a shear plane. State $\mathrm{C}$ is, thus, considered as a state of a damaged sample with the presence of a shear band. The permeability is measured by the same measurement technique as that used for the sample OP1. However, the excess pore pressure dissipation is allowed only through the drainage connected to the internal sample wall. Pore pressure changes are monitored by the pressure transducers connected to the external sample wall and to the sample bottom. The response of two pressure transducers, the water expelled and the numerical simulation of the tests are presented in Figs. 9 and 10. The estimated permeability at each step is presented in Table 1 . Note that the estimated permeability is representative of the response of the whole sample and not of the shear band. However, if the shear band was a preferential hydraulic path, this would be reflected in the global response of the sample, particularly for the pore pressure monitored on the external sample wall. The data show a reduction of permeability coefficients both parallel and perpendicular to the bedding after the drained triaxial compression. Interestingly, this result clearly shows that the damage induced by shearing, as opposed to extensional fractures, has no significant effect on the water transport properties of the sample, confirming the good sealing capacity of the OPA clay (see also Labiouse and Vietor 2013). The reduction in the permeability is attributed to the decrease in sample porosity due to the increase in the mean effective stress during the drained shearing test.

Examination of the data of the permeability test at $80{ }^{\circ} \mathrm{C}$ on the sheared sample (Fig. 9) shows evidence of faster pore pressure dissipation. The results of the numerical simulation confirm that the reduction of water viscosity upon heating (from $8.9 \times 10^{-4} \mathrm{~Pa} \quad \mathrm{~s}$ at $25^{\circ} \mathrm{C}$ to $3.5 \times 10^{-4} \mathrm{~Pa}$ s at $80^{\circ} \mathrm{C}$ ) is the reason for this faster dissipation. The slight increase in intrinsic permeability at $80{ }^{\circ} \mathrm{C}$ is related to the slight increase in sample porosity induced by drained heating. The LVDT transducers' responses during the heating-cooling cycle of the sheared sample confirm a reversible dilation/contraction, as shown in Fig. 11. However, we observe that the response is not exactly linear, but exhibits a quasi-bilinear shape. More tests would be needed in order to explore further this nonlinearity. The average thermal expansion coefficient estimated from this curve is equal to $7.1 \times 10^{-5}{ }^{\circ} \mathrm{C}^{-1}$, which is close to that measured on the intact sample $\left(6.3 \times 10^{-5}{ }^{\circ} \mathrm{C}^{-1}\right)$. The reversible response of the sheared sample OP2 during the heating cycle, as opposed to the irreversible contraction of the intact sample OP1, can be 

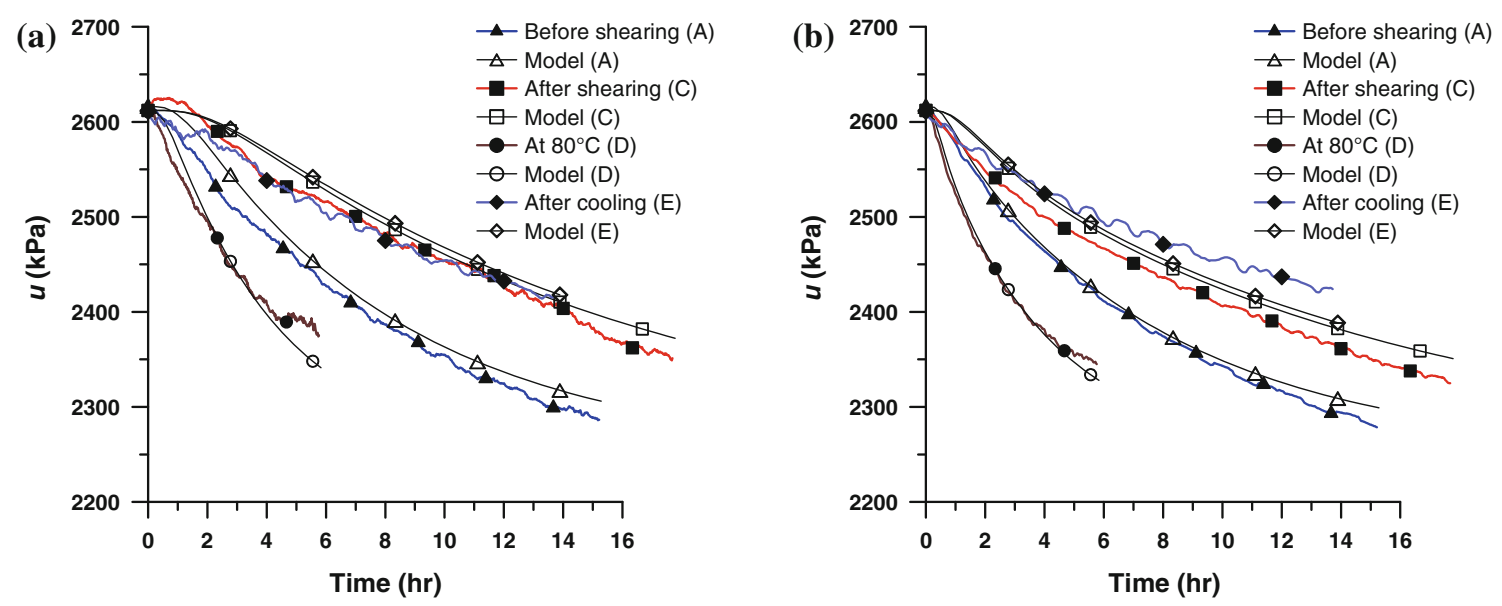

Fig. 9 Experimental data and model results for pore pressure dissipation during the transient permeability tests on sample OP2: a external wall transducer, $\mathbf{b}$ bottom transducer

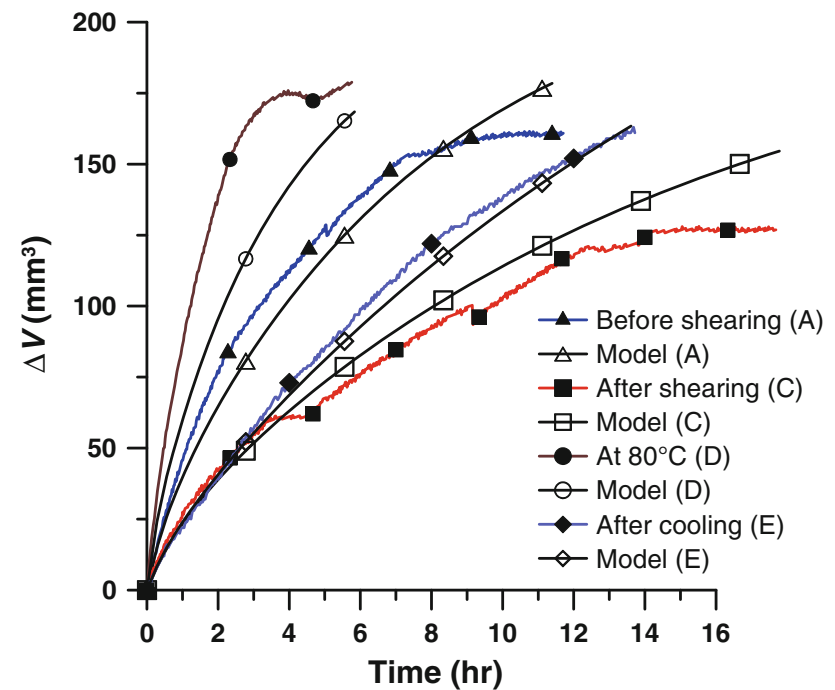

Fig. 10 Experimental data and model results for the volume of water expelled from the sample during the pore pressure dissipation of the permeability tests on sample OP2

Table 1 Estimated permeability for sample OP2

\begin{tabular}{llll}
\hline & $k_{\|}\left(\mathrm{m}^{2}\right)$ & $k_{\perp}\left(\mathrm{m}^{2}\right)$ & $S\left(\mathrm{~Pa}^{-1}\right)$ \\
\hline Before shearing, 25 $(\mathrm{A})$ & $5.0 \times 10^{-20}$ & $2.3 \times 10^{-20}$ & $1.9 \times 10^{-9}$ \\
After shearing, $25^{\circ}(\mathrm{C})$ & $2.9 \times 10^{-20}$ & $0.8 \times 10^{-20}$ & $1.8 \times 10^{-9}$ \\
At $80^{\circ} \mathrm{C}(\mathrm{D})$ & $3.9 \times 10^{-20}$ & $1.5 \times 10^{-20}$ & $1.8 \times 10^{-9}$ \\
After cooling, $25^{\circ}(\mathrm{E})$ & $2.9 \times 10^{-20}$ & $0.8 \times 10^{-20}$ & $1.9 \times 10^{-9}$ \\
\hline
\end{tabular}

explained by the prior hardening (extension of the yield surface) during the drained shearing test. This reversible response also explains the return of the permeability to its value before heating once the sheared sample is cooled down to $25^{\circ} \mathrm{C}$.

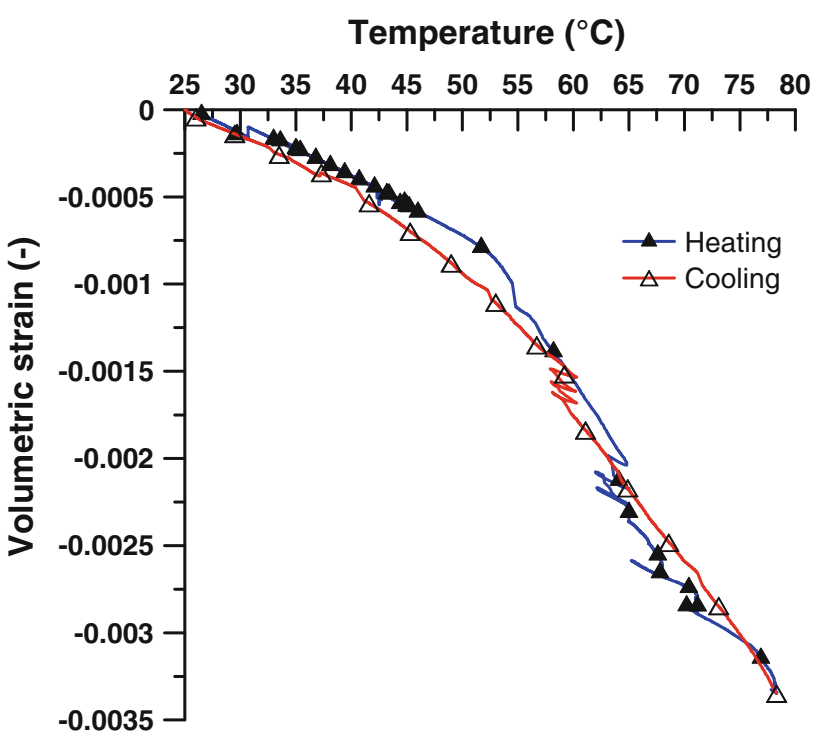

Fig. 11 Thermal volume change of the sheared sample OP2 during the drained heating-cooling cycle, measured by local strain linear variable differential transformer (LVDT) transducers

\subsection{Discussion on the Results of the Permeability Tests}

In the previous sections, two permeability tests on sample OP1 and four permeability tests on sample OP2 are presented. At first glance, the effect of heating on the permeability of the two samples seems opposite. Heating of sample OP1 reduces the permeability, while for sample OP2, an increase in permeability is observed. The explanation for this apparent contradiction can be found in the two different loading paths applied to these samples and to the resulting deformation. During heating up to $80{ }^{\circ} \mathrm{C}$ of the previously sheared sample, the material remains in the elastic domain, whereas during heating up to $80{ }^{\circ} \mathrm{C}$ of the intact sample, irreversible contraction is induced, as shown 
in Sect. 4.1. These interesting results show that heating could affect the sample permeability in two inverse ways. As long as no irreversible deformation is generated by heating, the permeability of the sample slightly increases due to elastic sample dilation, whereas when irreversible thermally induced contraction is generated, a reduction of the permeability is observed.

Another difference obtained from the back-analysis of these permeability tests concerns the evolution of the storage coefficient. No significant change is observed for sample OP2 as opposed to what is observed for sample OP1. Back-analysis of the permeability tests after saturation leads to the estimation of a higher initial value of the storage coefficient for sample OP1 $\left(4.3 \times 10^{-6} \mathrm{kPa}^{-1}\right)$ than for sample OP2 $\left(1.9 \times 10^{-6} \mathrm{kPa}^{-1}\right)$. This difference may be attributed to the fact that this sample was more disturbed, as it was extracted from a core situated at a distance of about $1 \mathrm{~m}$ from the excavation tunnel wall, while sample OP2 was taken from a core excavated at about $9 \mathrm{~m}$. More tests would be necessary in order to explore the effect of initial damage as well as the type of loading, heating or shearing on the storage coefficient, but this is beyond the scope of this paper.

The slight change of the intrinsic permeability of the damaged sample at higher temperature confirms the good self-sealing capacity of the OPA clay, even at high temperature. These results are also in good accordance with the permeability measurements performed in situ in the underground laboratory of ANDRA in Bure. As shown by Armand et al. (2013), shear fractures, as opposed to extensional fractures, do not significantly affect the permeability of the rock mass. As long as the shear fractures remain closed and saturated, the material recovers its undisturbed water permeability.

\section{Conclusion}

The effects of temperature changes on the water transport properties of intact and damaged Opalinus (OPA) clay samples were investigated in a recently developed hollow cylinder triaxial cell that allowed satisfactory saturation within a reasonable period of time, thanks to a small drainage length (the hollow cylinder thickness, i.e. $10 \mathrm{~mm}$ ).

The effect of the thermo-plastic contraction induced by heating-cooling cycles on the permeability of the intact OPA clay was studied in the first sample (OP1). The transient permeability tests run before and after the heating-cooling cycles clearly showed the decrease of both the permeability and the storage coefficient of the sample, due to the thermo-plastic contraction of the OPA clay.

The effects of temperature elevation on a damaged sample were investigated on the second sample (OP2), which was previously damaged by performing a standard drained shear test prior to being subjected to a heatingcooling cycle. The permeability tests run before and after shearing showed a small reduction in permeability attributed to global mechanical contraction of the sample, with no effect of the shear plane, confirming the excellent selfsealing property of OPA clay at ambient temperature. This property was also confirmed at higher temperature, with no significant effect of shear-type damage observed on the permeability of OPA clay at $80^{\circ} \mathrm{C}$.

The presence of the clay minerals guarantees the sealing properties of OPA clay. Similar results have been achieved on Boom clay, a potential host material for radioactive waste extracted from Mol in Belgium, which contains $55 \%$ clayey minerals. The permeability tests at ambient temperature and at $80{ }^{\circ} \mathrm{C}$ after sample shearing showed no significant change in the sample permeability (Monfared et al. 2012).

Note that, for both samples, the bedding planes are parallel to the hollow cylinder axis. One could, thus, ask what could be the response of samples with axes normal to bedding planes and to the possibility of cracks opening along bedding planes during mechanical unloading. Experimental studies of Davy et al. (2007) on Callovo-Oxfordian argillite samples showed that swelling tends to close the cracks and to increase their confinement. They showed that, after a relatively short time (on the order of 10 days), water flow within the crack drives the permeability back to very low values close to sound rock permeability. This gives confidence in the expectation that our experimental result could be extended to samples with axes normal to bedding planes. This will be verified in the near future.

All these laboratory and in situ observations thus confirm the self-sealing of shear fractures in clay host rocks. which is a major factor for nuclear waste repository safety.

Acknowledgments The authors wish to acknowledge the financial support provided by the European project TIMODAZ (F16 W-CT2007-036449), NAGRA and École des Ponts ParisTech for this research project. They wish to thank Tim Vietor (NAGRA) for providing the OPA clay samples and for the fruitful and enthusiastic support and discussions. The authors also wish to thank the technical team of Navier/CERMES (École des Ponts ParisTech) and, in particular, M. E. De Laure for his assistance in the experimental work. They also thank Yu Jun Cui, Siavash Ghabezloo and Anh-Minh Tang for the stimulating discussions.

\section{References}

Ai H, Young JF, Scherer GW (2001) Thermal expansion kinetics: method to measure permeability of cementitious materials: II, application to hardened cement pastes. J Am Ceram Soc 84(2):385-391. Erratum, J Am Ceram Soc 87(8):1611

Armand G, Leveau F, Nussbaum C, de La Vaissiere R, Noiret A, Jaeggi D, Landrein P, Righini C (2013) Geometry and properties 
of excavation-induced fractures at the Meuse/Haute-Marne URL drifts. Rock Mech Rock Eng. doi:10.1007/s00603-012-0339-6

Brace WF, Walsh JB, Frangos WT (1968) Permeability of granite under high pressure. J Geophys Res 73(6):2225-2236

Campanella RG, Mitchell JK (1968) Influence of temperature variations on soil behavior. J Soil Mech Found Eng Div 94(SM3):709-734

Cekerevac C, Laloui L (2004) Experimental study of thermal effects on the mechanical behaviour of a clay. Int J Numer Anal Meth Geomech 28:209-228

Coll C (2005) Endommagement des roches argileuses et perméabilité induite au voisinage d'ouvrages souterrains. Thèse de Doctorat de l'Université Joseph Fourier-Grenoble II, p 257

Davy CA, Skoczylas F, Barnichon JD, Lebon P (2007) Permeability of macro-cracked argillite under confinement: gas and water testing. Phys Chem Earth 32(8-14):667-680

Delage P, Sultan N, Cui YJ (2000) On the thermal consolidation of Boom clay. Can Geotech J 37:343-354

Delage P, Le TT, Tang AM, Cui YJ, Li XL (2007) Suction effects in deep Boom clay block samples. Géotechnique 57(2):239-244

Ghabezloo S, Sulem J, Saint-Marc J (2009) Evaluation of a permeability-porosity relationship in a low-permeability creeping material using a single transient test. Int J Rock Mech Min Sci 46(4):761-768

Habibagahi K (1977) Temperature effect and the concept of effective void ratio. Indian Geotech J 7(1):14-34

Hart DJ, Wang HF (2001) A single test method for determination of poroelastic constants and flow parameters in rocks with low hydraulic conductivities. Int J Rock Mech Min Sci 38:577-583

Hueckel T, Borsetto M (1990) Thermoplasticity of saturated soils and shales: constitutive equations. J Geotech Eng 116(12):1765-1777

Jobmann M, Polster M (2007) The response of Opalinus clay due to heating: a combined analysis of in situ measurements, laboratory investigations and numerical calculations. Phys Chem Earth 32(8-14):929-936

Kull H, Jockwer N, Zhang C-L, Wileveau Y, Pepa S (2007) Measurement of thermally-induced pore-water pressure increase and gas migration in the Opalinus Clay at Mont Terri. Phys Chem Earth 32(8-14):937-946

Labiouse V, Vietor T (2013) Laboratory and in situ simulation tests of the excavation damaged zone around galleries in Opalinus clay. Rock Mech Rock Eng. doi:10.1007/s00603-013-0389-4

Marschall P, Horseman S, Gimmi T (2005) Characterisation of gas transport properties of the Opalinus Clay, a potential host rock formation for radioactive waste disposal. Oil Gas Sci Technol Rev IFP 60(1):121-139
Martin CD, Lanyon GW (2003) Measurement of in-situ stress in weak rocks at Mont Terri Rock Laboratory, Switzerland. Int J Rock Mech Min Sci 40(7-8):1077-1088

Mazurek M (1999) Mineralogy of the Opalinus clay. In: Thury M, Bossart P (eds) Results of the hydrogeological, geochemical and geotechnical experiments, performed in 1996 and 1997. Swiss National Geological and Hydrogeological Survey. Geological report no. 23 , pp. $15-18$

Mohajerani M, Delage P, Monfared M, Sulem J, Tang AM, Gatmiri B (2011) Oedometric compression and swelling behaviour of the Callovo-Oxfordian argillite. Int J Rock Mech Min Sci 48(4): 606-615

Mohajerani M, Delage P, Sulem J, Monfared M, Tang AM, Gatmiri B (2013) The thermal volume changes of the Callovo-Oxfordian claystone. Rock Mech Rock Eng (in press)

Monfared M, Sulem J, Delage P, Mohajerani M (2011a) A laboratory investigation on thermal properties of the Opalinus claystone. Int J Rock Mech Rock Eng 44(6):735-747

Monfared M, Delage P, Sulem J, Mohajerani M, Tang AM, De Laure E (2011b) A new hollow cylinder triaxial cell to study the behavior of geo-materials with low permeability. Int J Rock Mech Min Sci 48(4):637-649

Monfared M, Sulem J, Delage P, Mohajerani M (2012) On the THM behaviour of a sheared Boom clay sample: application to the behaviour and sealing properties of the EDZ. Eng Geol 124:47-58

Morin R, Silva AJ (1984) The effects of high pressure and high temperature on some physical properties of ocean sediments. J Geophys Res 89(B1):511-526

Muñoz JJ (2006) Thermo-hydro-mechanical analysis of soft rock. Application to a large scale heating test and large scale ventilation test. $\mathrm{PhD}$ thesis, University Politecnica de Catalunya, $246 \mathrm{pp}$

Scherer GW (2006) Dynamic pressurization method for measuring permeability and modulus: I. Theory. Mater Struct 39:1041-1057

Sulem J, Vardoulakis I, Ouffroukh H, Boulon M, Hans J (2004) Experimental characterization of the thermo-poro-mechanical properties of the Aegion fault gouge. C R Geosci 336(4-5): $455-466$

Verruijt A (2013) Theory and problems of poroelasticity. Available online at: http://geo.verruijt.net/software/PoroElasticity2013.pdf. Delft University of Technology, the Netherlands

Zhang CL, Rothfuchs T, Su K, Hoteit N (2007) Experimental study of the thermo-hydro-mechanical behaviour of indurated clays. Phys Chem Earth 32(8-14):957-965 